\title{
Строение синтетических минералов- фторофосфатоцирконатов (гафнатов), установленное методом ЯМР
}

\author{
Слободюк А.Б. ${ }^{1}$, Годнева М.М. ${ }^{2}$ \\ ${ }^{1}$ Институт химии ФЕбРАН, Владивосток, атру@ich.dvo.ru \\ ${ }^{2}$ Институт химии и технологии редких элементов и минерального сырья КНЦ РАН, Апатиты, \\ motov@chemy.kolasc.net.ru
}

Аннотация. С использованием методов ЯМР и ЯМР ВМУ ${ }^{23} \mathrm{Na},{ }^{31} \mathrm{P},{ }^{19} \mathrm{~F},{ }^{1} \mathrm{H}$ исследовано строение, ионная и молекулярная подвижность в ряде фторофосфатометаллатов (ФФМе). Установлено, что фтор в соединениях координирован к переходному металлу (Me) и преимущественно занимает концевые позиции. При необходимости дополнения координационного числа Ме до 6, фтор образует мостиковые связи. Установлено наличие трансляционных движений молекул воды и ионов натрия в ряде соединений.

Ключевые слова: фториды, фосфаты, фторофосфатометаллаты, ЯМР, кристаллическое строение, ионная подвижность.

\section{The structure of the synthetic minerals - fluorophosphatozirconates (hafnates) estabilished with the NMR method}

\author{
Slobodyuk A.B. ${ }^{1}$, Godneva M.M. ${ }^{2}$ \\ ${ }^{1}$ Institute of chemistry, FEBRAS, Vladivostok,ampy@ich.dvo.ru \\ ${ }^{2}$ Institute of chemistry and technology of rare elements, Apatity, motov@chemy.kolasc.net.ru
}

\begin{abstract}
The structure and ionic mobility properties of the fluorophosphates metallates (FPMe) have been studied using the ${ }^{23} \mathrm{Na},{ }^{31} \mathrm{P},{ }^{19} \mathrm{~F},{ }^{1} \mathrm{H}$ NMR and MAS NMR methods. It is established that the fluorine in the FPMe is coordinated to the transition metal $(\mathrm{Me})$ and occupies predominately the terminal positions. In the compounds where it is necessary to supplement the Me coordination number to 6, the bridging fluorine bonds are formed. Several of FPMe are characterized with translational motions of water molecules and sodium cations.
\end{abstract}

Key words: fluorides, phosphates, fluorophosphatemetallates, NMR, crystalline structure, ionic mobility.

\section{Введение}

В работах (Годнева, Михайлова, 2012; Годнева с соавт., 2012 a; Годнева с соавт., 2012 b; Годнева с соавт., 2012 с, Годнева с соавт., 2013 а; Годнева с соавт., 2013 b; Годнева с соавт., 2013 с; Годнева с соавт., 201463 .) описаны новые фторофосфаты в системах $\mathrm{M}^{\mathrm{I} F}-\mathrm{M}^{\mathrm{IV}} \mathrm{F}_{4}-\mathrm{H}_{3} \mathrm{PO}_{4}-\mathrm{HF}-\mathrm{H}_{2} \mathrm{O}$ $\left(\mathrm{M}^{\mathrm{I}}\right.$ - щелочной металл, $\mathrm{M}^{\mathrm{IV}}-\mathrm{Zr}$, Hf). ФФМе являются разнообразными соединениями с перспективными свойствами.. Некоторые из ФФМе являются потенциальными люминофорами (Годнева, Борозновская, 2014 а), используются в качестве катодных материалов (Amatucci, Pereira, 2007), обладающих за счет индуктивного эффекта (Yamada с соавт., 2001) более высоким по сравнению с фосфатами окислительно-восстановительным потенциалом пары $\mathrm{M}^{2+} / \mathrm{M}^{3+}$. В связи с малым размером кристаллов, определение структуры этих соединений методом РСА затруднено. В то же время, ФФМе привлекательны в качестве объектов исследования методом ЯМР, поскольку содержат целый набор ядер с ненулевым магнитным моментом, взаимодействия между которыми малы. В настоящей работе приводится обзор сведений о строении, ионно-транспортных свойствах и истинных формулах ФФМе, установленных с применением метода ЯМР.

\section{Методика эксперимента}

Спектры ЯMP $\left({ }^{31} \mathrm{P},{ }^{19} \mathrm{~F},{ }^{1} \mathrm{H},{ }^{23} \mathrm{Na}\right)$ записывали на спектрометре Bruker Avance AV-300 в магнитном поле 7.05 Тл. Для регистрации спектров высокого разрешения использовали вращение образца под магическим углом (ВМУ) в роторе диаметром 4 мм с частотой 12-18 кГц и методику спинового эха Хана, синхронизированного с периодом вращения образца. В качестве эталона химическо- 
го сдвига $(\mathrm{XC}){ }^{19} \mathrm{~F}$ использовали $\mathrm{CFCl}_{3},{ }^{1} \mathrm{H}$ - тетраметилсилан, ${ }^{31} \mathrm{P}-85 \% \mathrm{H}_{3} \mathrm{PO}_{4},{ }^{23} \mathrm{Na}$ - разбавленный водный раствор $\mathrm{NaCl}$.

\section{Обсуждение результатов}

К настоящему времени исследован ряд фосфатофторидных соединений циркония и гафния, в которых M.o. F:Ме меняется от 3 до 2/3, при этом соответствующее отношение для фосфатной группы возрастает от $1 / 2$ до 5/3. Наиболее близки к фторидным соединения состава $\mathrm{MMe}_{2} \mathrm{~F}_{6} \mathrm{PO}_{4} \cdot 4 \mathrm{H}_{2} \mathrm{O}$ $(\mathrm{M}=\mathrm{Na}, \mathrm{Cs} ; \mathrm{Me}=\mathrm{Zr}$, Hf) (Годнева, $2012 \mathrm{a}$; Годнева, $2013 \mathrm{a}$; Годнева, $2013 \mathrm{~b}$; Годнева, $2012 \mathrm{c}$; Слободюк, Годнева, 2019; Слободюк с соавт., 2015). М.о. числа атомов фтора и кислорода (исключая кислород молекул воды), которые непосредственно могут входить в координацию атомов переходного металла к числу последних составляет $\mathrm{L}_{\mathrm{p}}: \mathrm{Me}=(4+6): 2=5$. Поскольку минимально возможное КЧ Ме равно 6, следует ожидать, что координационная сфера Ме будет достраиваться при помощи молекул воды или за счет образования мостиковых связей включающих атомы фтора.

Спектры ЯМР ВМУ ${ }^{19} \mathrm{~F}$ этих соединений со-

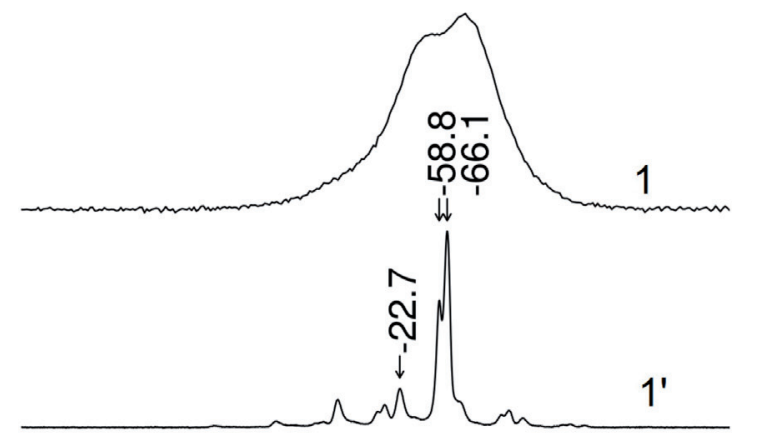
держат три сигнала (рис. 1). Анизотропия экранирования атомов фтора, соответствующих сигналу в слабом магнитном поле заметно выше, чем для двух других, на что указывают интенсивности боковых полос от вращения образца. Как известно, величина анизотропии магнитного экранирования фтора коррелирует с типом связи: для концевых атомов она заметно выше, чем для мостиковых (Youngman, Sen, 2005; Габуда с соавт., 1987). Таким образом, в структуре соединения имеются концевые и два типа мостиковых атомов фтора. Форма статических спектров, а именно, наличие дублета в центральной части спектра, указывает на заметную величину диполь-дипольного взаимодействия между мостиковыми атомами $\left(\mathrm{r}_{\mathrm{F}-\mathrm{F}}=2.56 \AA\right)$.

На основании полученных данных можно предположить, что структура соединений $\mathrm{MMe}_{2} \mathrm{PO}_{4} \mathrm{~F}_{6} \cdot 4 \mathrm{H}_{2} \mathrm{O}$ образована семивершинниками $\mathrm{MeO}_{2} \mathrm{~F}_{5}^{5-}$, объединенными при помощи ионов фтора и фосфатных анионов в двойные слои. Все атомы кислорода фосфатных групп и 2/3 атомов фтора являются мостиковыми. Между слоями расположены щелочные катионы.

Интересно отметить, что для соединения натрия при более высокой неэквивалентности мостиковых атомов, наблюдаемой в спектре ЯМР ВМУ, расщепление дублета уменьшено. Кроме того, если в спектрах ЯМР ВМУ ${ }^{31} \mathrm{P}$ ФФЦ цезия содержится по одному сигналу, то спектр ФФЦ натрия содержит два сигнала различной интенсивности. Можно предположить, что указанные эффекты вызваны малым радиусом и поляризуемостью ионов натрия, благодаря чему возрастает отклонение формы полиэдров $\mathrm{MeO}_{2} \mathrm{~F}_{5}^{5-}$ от октаэдрической. 


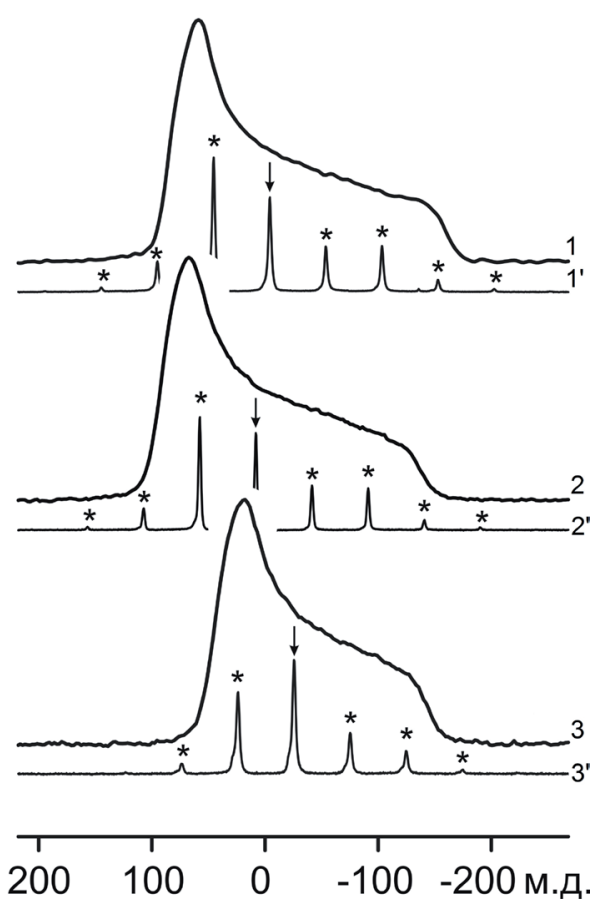

Рис. 2. Статические $(1,2,3)$ и ВМУ $\left(1\right.$ ', 2' 3') спектры ЯМР ${ }^{19} \mathrm{~F}$ соединений: $\mathrm{K}_{3} \mathrm{Zr}_{3} \mathrm{~F}_{3}\left(\mathrm{HPO}_{4}\right)_{3}\left(\mathrm{PO}_{4}\right)_{2},\left(1,1^{\prime}\right), \mathrm{Rb}_{3} \mathrm{Zr}_{3} \mathrm{~F}_{3}\left(\mathrm{HPO}_{4}\right)_{3}\left(\mathrm{PO}_{4}\right)_{2}$ $\left(2,2^{\prime}\right)$ и $\mathrm{Rb}_{3} \mathrm{Hf}_{3} \mathrm{~F}_{3}\left(\mathrm{HPO}_{4}\right)_{3}\left(\mathrm{PO}_{4}\right)_{2} \cdot\left(3,3^{\prime}\right)$.

Fig. 2. Staticand MAS ${ }^{19} \mathrm{FNMR}$ spectra of $\mathrm{Z}_{3} \mathrm{Zr}_{3} \mathrm{~F}_{3}\left(\mathrm{HPO}_{4}\right)_{3}\left(\mathrm{PO}_{4}\right)_{2},\left(1,1^{\prime}\right)$, $\mathrm{Rb}_{3} \mathrm{Zr}_{3} \mathrm{~F}_{3}\left(\mathrm{HPO}_{4}\right)_{3}\left(\mathrm{PO}_{4}\right)_{2}\left(2,2^{\prime}\right)$ и $\mathrm{Rb}_{3} \mathrm{Hf}_{3} \mathrm{~F}_{3}\left(\mathrm{HPO}_{4}\right)_{3}\left(\mathrm{PO}_{4}\right)_{2} .\left(3,3^{\prime}\right)$.

Спек т ры Я М Р ${ }^{19} \mathrm{~F}$ с о един ен и й $\mathrm{M}_{3} \mathrm{Me}_{3} \mathrm{~F}_{3}\left(\mathrm{HPO}_{4}\right)_{3}\left(\mathrm{PO}_{4}\right)_{2}(\mathrm{M}-\mathrm{K}, \mathrm{Rb} ; \mathrm{Me}-\mathrm{Zr}, \mathrm{Hf})$ (Годнева, 2013 с; Годнева с соавт., 2010; Годнева с соавт., 2011; Годнева с соавт., 2008) определяются аксиальносимметричными тензорами магнитного экранирования фтора (рис. 2). Поскольку в известных структуpax кислых фосфатов группа ОН ионов $\mathrm{HPO}_{4}{ }^{2-}$, как правило, не входит в координацию комплексообразующего металла, M.o.L $:$ :Me в этой группе соединений равно $(3 \cdot 3+2 \cdot 4+3): 3 \stackrel{p}{=} 6.67$. Данные ЯМР указывают на то, что в соединении имеются только по одному типу концевых атомов фтора, ионов $\mathrm{PO}_{4}^{3-}$ и $\mathrm{HPO}_{4}{ }^{2-}$. Если предположить, что оба типа фосфатных групп координированы к трем атомам Ме, соединения могут иметь строение, указанное на рис. 3. Структура построена из слоёв, в которых каждый атом Ме соединен мостиковой связью с тремя гидрофосфатными и двумя фосфатными ионами. Шестое координационное место при атоме Ме занимает фтор (на рисунке не показан).

\section{Заключение}

Согласно полученным данным, атомы фтора в исследованных ФФМе координированы к атому циркония или гафния. При величине м.o. $\mathrm{L}_{\mathrm{p}}$ : Me ( $\mathrm{Lp}$ - сумма количеств атомов кислорода и фтора) менее 6 фтор образует мостиковые связи, объединяя между собой координационные полиэдры
Можно предположить, что ФФМе может быть построен аналогично представителям группы фторофосфтов $\mathrm{Na}_{3} \mathrm{M}_{2}\left(\mathrm{PO}_{4}\right)_{2} \mathrm{~F}_{3}(\mathrm{M}=\mathrm{Al}, \mathrm{Ga}$, $\mathrm{V}, \mathrm{Cr}, \mathrm{Fe})$ и $\mathrm{Al}\left(\mathrm{H}_{2} \mathrm{O}\right)_{4}\left[\mathrm{Ca}_{2}\left(\mathrm{SO}_{4}\right)_{2} \mathrm{~F}_{2} \mathrm{Cl}\right]$ (влодавецит-минерал, впервые обнаруженный на Камчатке) (Le Meins c соавт., 1999). Структуры построены из димеров $\mathrm{M}_{2} \mathrm{O}_{8} \mathrm{X}_{3}(\mathrm{X}=\mathrm{F}, \mathrm{Cl})$, объединенных с помощью тетраэдрических анионов в слои, причем каждый димер принадлежит одновременно двум слоям. В пустотах образованного таким образом каркаса находятся катионы. В структуре $+4+2) / 2=6$. Формально, связь NZP и ФФМе можно представить следующей формулой: $\mathrm{CsHf}_{2}\left(\mathrm{PO}_{4}\right)_{3}+2 \mathrm{HF}+2 \mathrm{H}_{2} \mathrm{O}=$ $\mathrm{CsHf}_{2} \mathrm{~F}_{2}\left(\mathrm{HPO}_{4}\right)_{2}\left(\mathrm{PO}_{4}\right) \cdot 2 \mathrm{H}_{2} \mathrm{O}$, при этом каждой разорванной связи $\mathrm{P}-\mathrm{O}-\mathrm{Hf} \rightarrow$ P-OH отвечает фтор в концевом положении. Наличие избытка вакантных структурных позиций приводит к тому, что подвижность молекул воды в соединении достаточно высока.

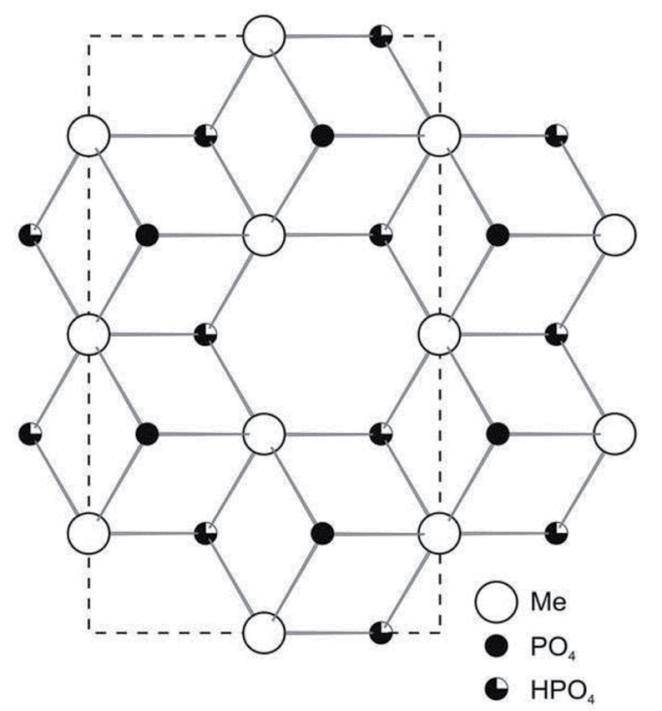

Рис. 3. Фрагмент слоя $\mathrm{M}_{3} \mathrm{Me}_{3} \mathrm{~F}_{3}\left(\mathrm{HPO}_{4}\right)_{3}\left(\mathrm{PO}_{4}\right)_{2}$. Пунктиром обозначена элементарная ячейка.

Fig. 3. Fragment of the layer in the $\mathrm{M}_{3} \mathrm{Me}_{3} \mathrm{~F}_{3}\left(\mathrm{HPO}_{4}\right)_{3}\left(\mathrm{PO}_{4}\right)_{2}$ structure. The dashed line marks the elementary cell. 
Me. Можно заметить, что с увеличением м.o.F:Ме имеется тенденция к сдвигу сигналов ЯMP ${ }^{19} \mathrm{~F}$ в направлении сильного магнитное поля. Зависимость сдвига сигналов ЯМР ${ }^{19} \mathrm{~F}$ от природы катиона соответствует закону Гутовского-Гофмана. Для соединений гафния характерно расположение сигналов ЯМР ${ }^{19} \mathrm{~F}$ в более сильном магнитном поле по сравнению с их циркониевыми аналогами, а сигналов ЯМР ${ }^{31} \mathrm{P}$ - в более слабом поле. Для многих из рассмотренных ФФМе характерно наличие реориентационных и диффузионных движений молекул воды, а в двух из них - и диффузионных движений катионов натрия. Последнее позволяет рассчитывать на возможность практического применения ФФМе в качестве твердых электролитов в числе прочего в натрий-ионных химических источниках тока.

\section{Литература}

1. Габуда С.П., Гончарук В.К., В.Я. К., Куликов А.П., Петровский Г.Т. Определение структуры ближнего порядка фторцирконатных стекол по данным анизотропии химических сдвигов сигналов ЯМР ${ }^{19} \mathrm{~F} / /$ Доклады Академии наук СССР, 1987. Т. 296. № 5. С. 1150-1153.

2. Гобечия Е.Р., Кабалов Ю.К., Петьков В.И., Суханов М.В. Кристаллические структуры двойных ортофосфатов цезия-циркония и бария-циркония // Кристаллография. 2004. Т. 49. № 5. С. 829-834.

3. Годнева М.М., Мотов Д.Л., Борозновская Н.Н., Кузнецов В.Я. Синтез в системе $\mathrm{ZrO}_{2} \mathrm{H}_{3} \mathrm{PO}_{4}-\mathrm{RbF}_{2} \mathrm{H}_{2} \mathrm{O}$ фторофосфатоцирконатов рубидия и их люминесцентные свойства // Журнал неорганической химии. 2010. T. 55. № 12. С. 1957-1962.

4. Годнева М.М., Мотов Д.Л., Залкинд О.А. Система $\mathrm{ZrO}\left(\mathrm{NO}_{3}\right)_{2}-\mathrm{H}_{3} \mathrm{PO}_{4}-\mathrm{KF}(\mathrm{HF})-\mathrm{H}_{2} \mathrm{O}$ при отношениях $\mathrm{PO}_{4} /$ $\mathrm{Zr}=0.5-1.6$ как основа фазообразования //Журнал неорганической химии. 2011. Т. 56. № 1. С. 13-19.

5. Годнева М.М., Беляевский А.Т., Залкинд О.А. Фазообразование в системе $\mathrm{HfO}\left(\mathrm{NO}_{3}\right)_{2}-\mathrm{H}_{3} \mathrm{PO}_{4}-\mathrm{CsF}(\mathrm{HF})-$ $\mathrm{H}_{2} \mathrm{O} / /$ Журнал неорганической химии. 2012 а. Т. 57. № 12. С. 1709-1714.

6. Годнева М.М., Мотов Д.Л., Рыськина М.П., Пахомовский Я.А. Фазообразование в системе $\mathrm{ZrO}\left(\mathrm{NO}_{3}\right)_{2}-$ $\mathrm{H}_{3} \mathrm{PO}_{4}-\mathrm{CsF}(\mathrm{HF})-\mathrm{H}_{2} \mathrm{O} / /$ Журнал неорганической химии, 2012 b. Т. 57. № 7. С. 1107-1114.

7. Годнева М.М., Михайлова Н.Л. Фазообразование по разрезам системы $\mathrm{HfO}\left(\mathrm{NO}_{3}\right)_{2}-\mathrm{H}_{3} \mathrm{PO}_{4}-\mathrm{RbF}-\mathrm{H}_{2} \mathrm{O} / /$ Журнал неорганической химии. 2012. Т. 57. № 6. С. 949-956.

8. Годнева М.М., Борозновская Н.Н., Михайлова Н.Л. Термическая устойчивость и рентгенолюминесцентные свойства фторофосфатогафнатов цезия // Журнал неорганической химии. 2013 а. Т. 58. № 5. С. 571-577.

9. Годнева М.М., Залкинд О.А., Беляевский А.Т. Исследование строения фторофосфатоцирконатов (гафнатов) щелочных металлов методами ИК спектроскопии и кристалломорфологии //Журнал структурной химии. 2013 б. Т. 54. № 4. С. 651-656.

10. Годнева М.М., Борозновская Н.Н. Люминесценция потенциальных рентгенолюминофоров на основе фтористых, фторосульфатных и фторофосфатных соединений элементов подгруппы титана //-Перспективные материалы. 2014 а. № 6. С. 32-41.

11. Годнева М.М., Кузнецов В.Я., Рыськина М.П., Семушин В.В., Михайлова Н.Л. Фазообразование в системе $\mathrm{ZrO}\left(\mathrm{NO}_{3}\right)_{2}-\mathrm{NaF}(\mathrm{HF})-\mathrm{H}_{3} \mathrm{PO}_{4}-\mathrm{H}_{2} \mathrm{O}$ при $20{ }^{\circ} \mathrm{C} / /$ Журнал неорганической химии, 2014 b. T. 59 . № 8. C. $1071-1080$.

12. Годнева М.М. Синтез фторофосфатогафнатов калия при $20^{\circ} \mathrm{C} / /$ Журнал неорганической химии. 2014. T. 59. № 2. C. 160-165.

13. Слободюк А.Б., Диденко Н.А., Годнева М.М. Исследование строения гидратированных фторофосфатоцирконатов (гафнатов) методом ЯМР // Журнал структурной химии. 2015. Т. 56. С. 1111-1117.

14. Слободюк А.Б., Кавун В.Я., Годнева М.М. Особенности строения кислых фторофосфато-цирконатов (гафнатов) по данным ЯМР ${ }^{9} \mathrm{~F},{ }^{31} \mathrm{P},{ }^{1} \mathrm{H} / /$ Журнал структурной химии. 2016. Т. 57. № 2. С. 353-358.

15. Слободюк А.Б., Годнева М.М. Строение гидратированных фторофосфатоцирконатов натрия по данным ЯМР // Журнал структурной химии. 2019. Т. 60. № 4. С. 600-608.

16. Amatucci G.G., Pereira N. Fluoride based electrode materials for advanced energy storage devices //Journal of Fluorine Chemistry. 2007. V. 128. N. 4. P. 243-262.

17. Le Meins J.M., Crosnier-Lopez M.P., Hemon-Ribaud A., Courbion G. Phase transitions in the $\mathrm{Na}_{3} \mathrm{M}_{2}\left(\mathrm{PO}_{4}\right)_{2} \mathrm{~F}_{3}$ Family $\left(\mathrm{M}=\mathrm{Al}^{3+}, \mathrm{V}^{3+}, \mathrm{Cr}^{3+}, \mathrm{Fe}^{3+}, \mathrm{Ga}^{3+}\right)$ : synthesis, thermal, structural, and magnetic studies // Journal of Solid State Chemistry. 1999. V. 148. N. 2. P. 260-277.

18. Yamada A., Chung S.C., Hinokuma K. Optimized $\mathrm{LiFePO}_{4}$ for Lithium Battery Cathodes //Journal of The Electrochemical Society. 2001. V. 148. N. 3. P. A224-A229.

19. Youngman R.E., Sen S. A high-resolution ${ }^{19} \mathrm{~F}$ NMR spectroscopic study of barium fluorozirconate glasses and related crystals // Solid State Nuclear Magnetic Resonance. 2005. V. 27. N. 1-2. P. 77-89. 